\title{
Leakage after Pancreaticoduodenectomy
}

\author{
Case Report
}

\section{M.A. Boermeester}

Department of Surgery, Academic Medical Center, Amsterdam, The Netherlands

\author{
Key Words \\ Pancreaticoduodenectomy · Complications · Pancreatic \\ surgery · Anastomotic leakage $\cdot$ Pseudocyst
}

\section{Case Report}

A 54-year-old male was admitted to our hospital because of a pancreatic tumor with obstructive jaundice. ERCP showed an abnormal ampulla and biopsies were taken, which revealed a neuroendocrine tumor. Somatostatin receptor scintigraphy confirmed this diagnosis, showing a pathological zone in the bile duct area. A diagnostic laparoscopy was performed, which revealed no metastatic disease. A few weeks later, a pylorus-preserving pancreaticoduodenectomy (PPPD) was performed. The procedure was uneventful. However, on the 6th postoperative day, the patient developed fever, abdominal distention and increased abdominal pain. In addition, the patient displayed septic parameters (blood pressure 100/50 mm Hg; tachypnea, $\mathrm{PaO}_{2}$ $7.5 \mathrm{kPa}, \mathrm{O}_{2}$ saturation $85 \%$ without oxygen supply). The drain production was $100 \mathrm{ml} /$ day and had a turbid aspect. Amylase level of the drain fluid was $16,034 \mathrm{U} / \mathrm{ml}$. Ultrasonography was performed the same day and showed a moderate fluid collection in the former pancreatic head area.

\section{Question}

What is your next diagnostic/therapeutic step?

A Further diagnostic work-up with abdomiAudience's response nal CT scan and percutaneous drainage if possible

B Relaparotomy with dismantling of pancreaticojejunostomy and resection of the pancreas remnant
C Relaparotomy with dismantling of pancreaticojejunostomy and pancreatic duct occlusion with Tissucol

D Relaparotomy for drainage and drain placement only

\section{Comment}

Severe complications following PPPD are due largely to leakage from the pancreaticojejunostomy, infection, or postoperative hemorrhage. Different surgical techniques of PPPD have been tried to reduce the incidence or at least the severity of the pancreatic leakage: (a) transanastomotic splinting of the pancreatic duct, (b) prophylactic octreotide, (c) open stump management, (d) ligation, (e) occlusion of the pancreatic duct with Ethibloc (prolamine), Tissucol (a multicomponent fibrin sealant), or neoprene, and (f) various anastomosis techniques.

Overall, 4-9\% of patients need a reoperation for major complications after a pancreaticoduodenectomy. Complications requiring surgical reintervention strongly increase the risk of postoperative mortality from about $5 \%$ to at least $25 \%$. Nonsurgical management of postoperative complications, if possible, is preferred. However, the choice between nonsurgical and surgical management of leakage of the pancreas anastomosis highly depends on the present clinical condition of the patient, the extent of the intra-abdominal contamination, and the efficacy of the intra-abdominal drains already in place. In this patient, the drain fluid contained high levels of amylase, indicating at least a partial drainage of the leak. However, this patient rapidly developed a generalized sepsis with

\begin{tabular}{ll}
\hline KARGER & ( ) 2002 S. Karger AG, Basel \\
0253-4886/02/0192-0135\$18.50/0 \\
$\begin{array}{l}\text { Fax +4161306 1234 } \\
\begin{array}{l}\text { E-Mail karger@karger.ch } \\
\text { www.karger.com }\end{array}\end{array}$ & $\begin{array}{l}\text { Accessible online at: } \\
\text { www.karger.com/journals/dsu }\end{array}$
\end{tabular}

Dr. M.A. Boermeester, Surgeon

Academic Medical Center, Department of Surgery (G4-127)

Meibergdreef 9

NL-1105 AZ Amsterdam (The Netherlands)

Tel. +31 20 5662666, Fax +31 20 6914858, E-Mail m.a.boermeester@amc.uva.nl 


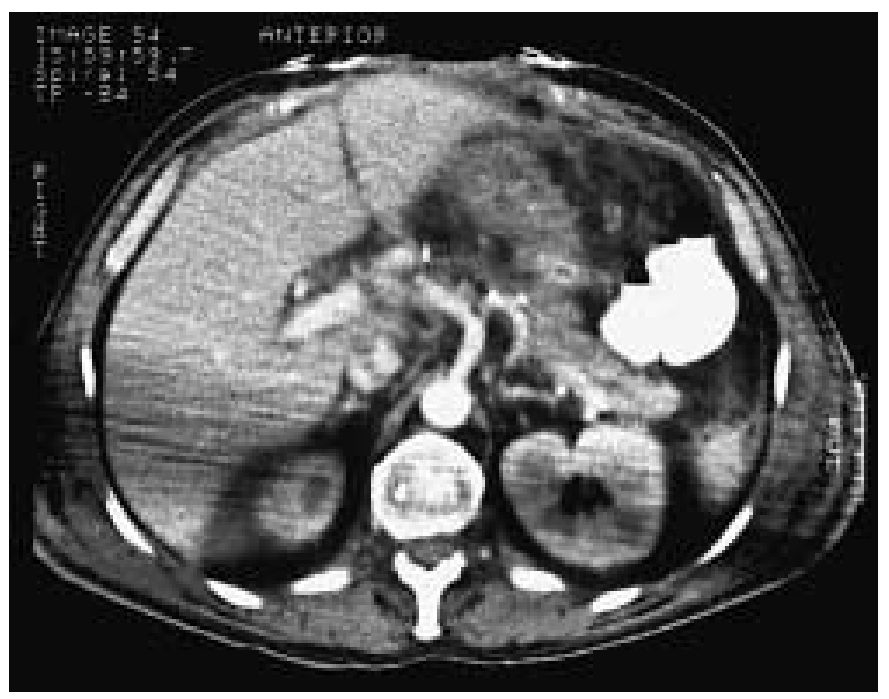

Fig. 1. Follow-up abdominal CT scan was made because of persistent pancreatic leakage, showing no fluid collections and adequate contrast enhancement of the remnant tail.

respiratory failure that warranted immediate and rigorous control of the source.

\section{Case Report (Continued)}

Leakage of the end-to-side pancreaticojejunostomy $(\mathrm{PJ})$ was confirmed at reoperation, which was performed without further diagnostic work-up. The PJ was dismantled, drains were placed, and the pancreatic duct of the pancreas remnant was occluded with Tissucol. Postoperatively, the patient was transferred to the ICU. The following 2 days no improvement of his septic parameters was seen, and on the 8th postoperative day the patient's condition deteriorated even further. Septic parameters: a cardiac output of $10.2 \mathrm{l} / \mathrm{min}$, a cardiac index of 5.1 and a systemic vascular resistance (SVR) $<500$; increasing dosages of norepinephrine and dopamine to maintain his blood pressure were needed; mechanical ventilation (IPPV). Drain production $200 \mathrm{ml} /$ day, turbid (not purulent), high amylase level.

\section{Question}

What is your next diagnostic/therapeutic step?

Audience's response

A Wait and see, abdominal CT scan, antibiotics

B Relaparotomy for drainage

C Relaparotomy for drainage, resection of the pancreas remnant only if necrosis

D Relaparotomy for resection of the pancreas remnant

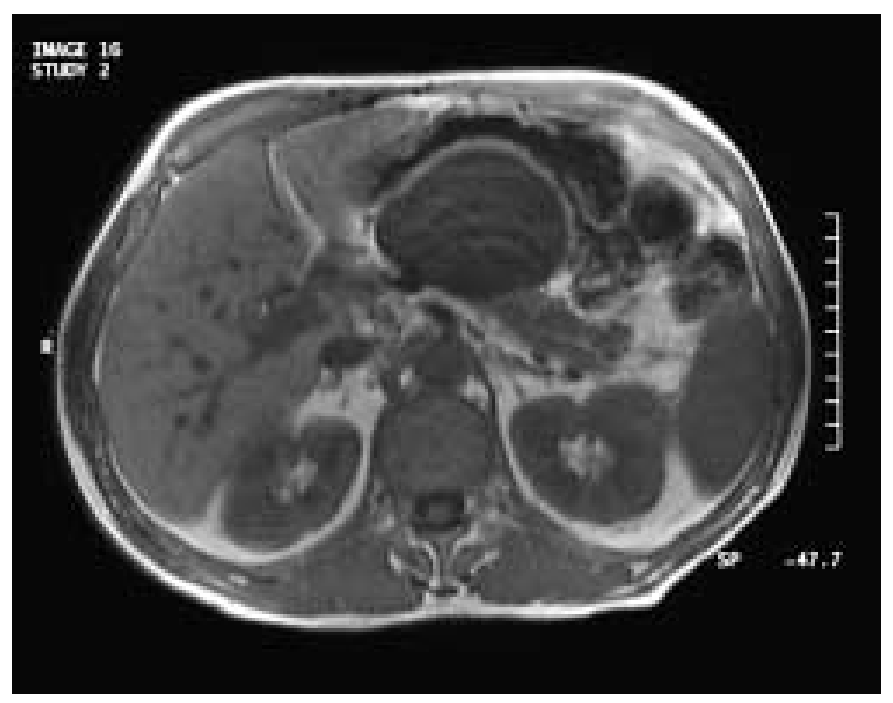

Fig. 2. MRI of the thick-walled pseudocyst at the proximal end of the remnant pancreatic tail and adjacent to the dorsal gastric wall, 1.5 years after PPPD

\section{Comment}

During the first reoperation an attempt was made to preserve the pancreas remnant. Although some reports have been published that the technique of duct occlusion appears to be a safe alternative for pancreatic anastomosis, data on its use for anastomotic leakage of the PJ are scarce. The attempt in this patient clearly failed and a more definite solution for the septic source was needed. Drainage only is not likely to reverse the situation, since the current abdominal drain contains turbid fluid with a high amylase level without improving the patient's condition.

\section{Case Report (Continued)}

Indeed, a resection of the pancreas remnant without splenectomy was performed. A tiny peace of pancreas tail ('tip of a knife') was left in situ to reduce endocrine pancreas insufficiency. Again, drains were placed in the lesser sac. Postoperatively, amylase levels in drain fluid remained high $(670,000 \mathrm{U} / \mathrm{ml})$, but his clinical condition improved. A follow-up CT scan (fig. 1) showed no fluid collections, but also that there was a considerable part of the pancreatic tail left in situ. Six weeks after PPPD, the patient was discharged from the ICU and returned to the ward.

There was a persistent leakage of pancreas fluid from the tail remnant, which drained adequately via the abdominal drain. After accidental removal of the intra-abdominal drain a CT scan was performed, showing a fluid collection in the lesser sac in contact with the dorsal gastric wall. The persistent contained leakage of the pancreas was managed by endoscopic transgastric drainage with stent placement. The stent remained in situ for 2 months. The patient was dis- 


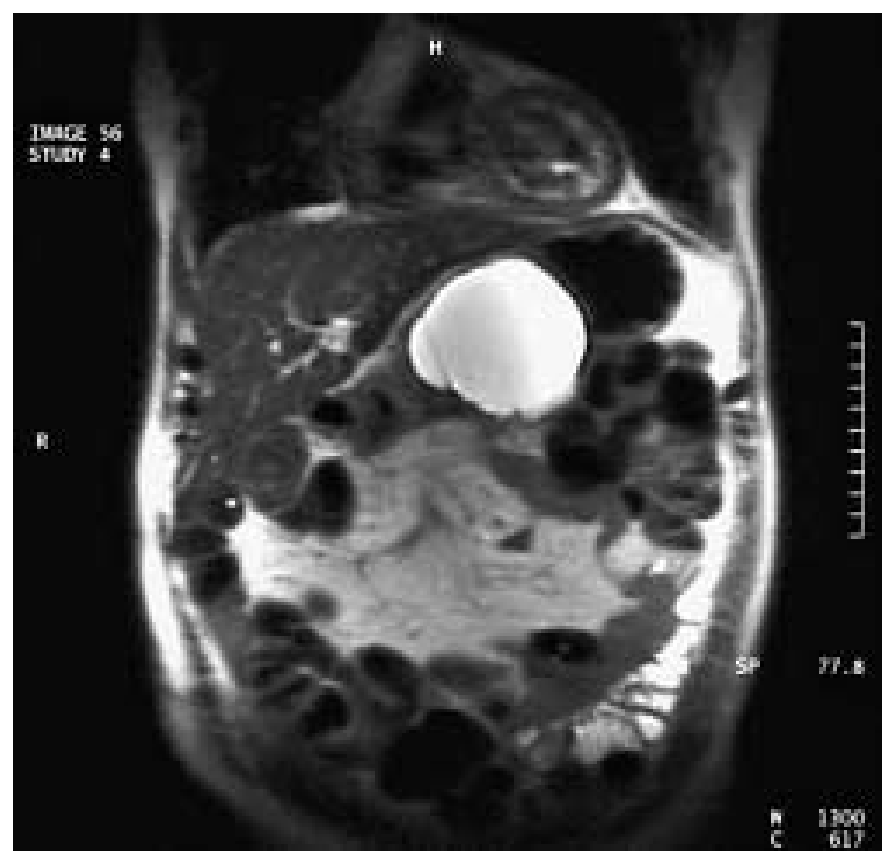

Fig. 3. Frontal image (MRI) of the pseudocyst showing a close relation between the pseudocyst and the stomach.

charged from the hospital in good condition with normal oral intake 3 months after PPPD.

A large pseudocyst adjacent to the pancreas tail was found on routine abdominal CT scan 1.5 years after surgery. The patient has no complaints. In figures 2 and 3 , the pseudocyst is depicted on T1 and T2 MRI.

\section{Question}

What is your next step?
A Surgical transgastric drainage
B Laparoscopic transgastric drainage
D Wait and see
$11 \%$
$27 \%$
$8 \%$

Audience's

$54 \%$

\section{Comment}

Pseudocysts can be treated by endoscopic cystogastrostomy or transpapillary stenting as an alternative to surgery. Common indications for drainage include pain, gastric outlet obstruction, biliary obstruction or cyst size $>6 \mathrm{~cm}$. The safety and efficacy of endoscopic drainage of pancreatic pseudocysts have been shown in many series. Endoscopic ultrasonography is useful for selecting the puncture site of the gastric wall. The optimal site is a point

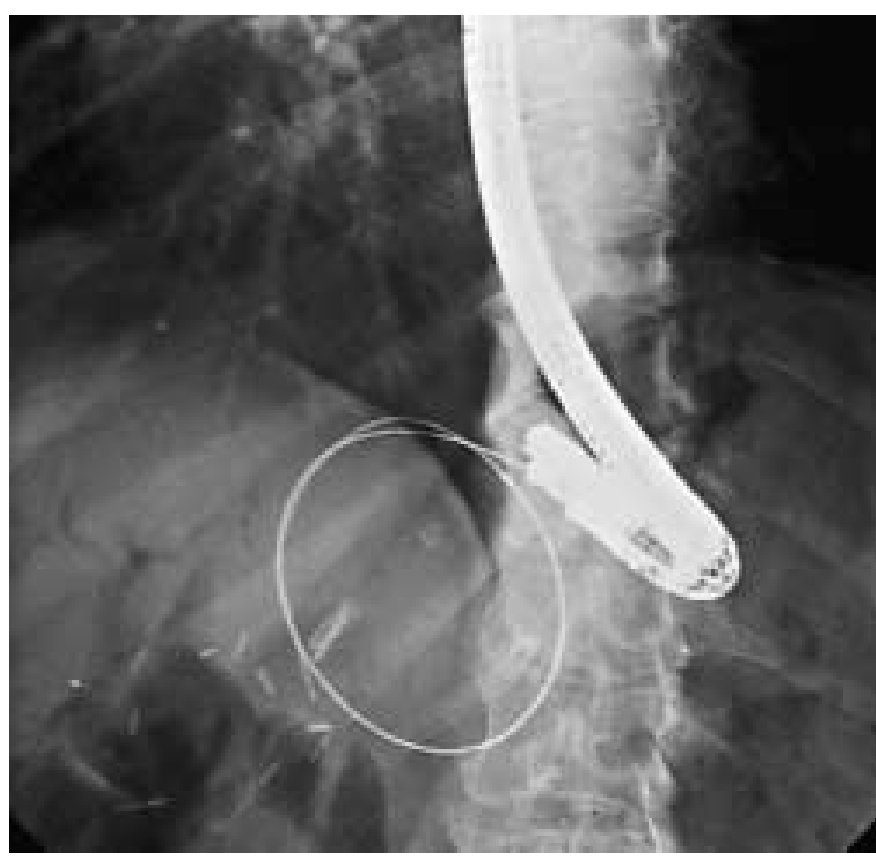

Fig. 4. Endoscopic transgastric drainage of the pseudocyst. The guidewire is curled in the cystic cavity.

with close apposition between the pseudocyst and the gastric wall without intervening vessels. When the drainage site does not meet these criteria, free perforation or hemorrhage may occur. When the local situation permits a safe endoscopic procedure, surgery can be avoided. For infected pseudocysts, percutaneous (US- or CT-guided) drainage may also be a minimal invasive alternative to surgery, depending on the localization of the pseudocyst.

This pseudocyst originated from the proximal end of the pancreatic tail remnant, being an end stage of a persistent pancreatic fistula. In this patient, the main indication for drainage was the cyst size of $>6 \mathrm{~cm}$. The close apposition between the thick-walled cyst and the dorsal gastric wall justified an endoscopic transgastric procedure.

\section{Case Report (Continued)}

An endoscopic transgastric drainage was performed without complications. Figure 4 depicts the guidewire in the pseudocyst. Three months later the procedure was repeated because of a recurrent pseudocyst. No pseudocyst was found during subsequent follow-up. 